(C) 1982. The Genetical Society of Great Britain

\title{
GENETIC CONTROL OF MEIOTIC PAIRING IN RYE
}

\author{
T. NARANJO* and O. PALLA ${ }^{\dagger}$ \\ * Departamento de Genética, Facultad de Ciencias, Universidad de Oviedo, Oviedo, \\ Spain; † Departamento de Genética, Facultad de Biolog/a, Universidad Complutense, \\ Madrid, Spain
}

Received 27.vii.81

\section{SUMMARY}

\begin{abstract}
Meiotic pairing in euploid rye-triticale hybrids $(A B R R, 2 n=28)$ is compared with that in three hypoaneuploid $A B R R$ hybrids, two with $2 n=26$ chromosomes and one with $2 n=27$, also obtained from the cross triticale by rye. The results show that the application of hypoaneuploidy compensated by homoeologous chromosomes is useful in the study of genetic control of meiotic pairing in diploid species. The aneuploid with $2 n=27$ chromosomes was identified as mono-5R by $C$-banding; its meiotic pairing indicated that chromosome $5 \mathrm{R}$ of rye is a strong promoter of homologous rye pairing and is also able to influence non-homologous (probably homoeologous) wheat chromosome pairing. This result reinforces Feldman's (1968) view that the $P h$ locus of hexaploid wheat arose by mutation of a promoter gene.
\end{abstract}

\section{INTRODUCTION}

THE $A, B$, and $D$ genomes of hexaploid wheat (Triticum aestivum, $2 n=$ $6 x=42)$ derive from three different but related diploid species $(2 n=2 x=$ 14) within the subtribe Triticinae (Kihara, 1919; Sax, 1922; McFadden and Sears, 1946; Riley, Unrau and Chapman, 1958; Feldman, 1978). The corresponding homoeologous chromosomes of the three different genomes are genetically closely related, as shown by their ability to compensate for each other in nullisomic-tetrasomic combinations (Sears, 1952). Consequently, loss of chromosome segments, as in ditelocentrics, or even whole chromosomes, as in monosomics and nullisomics, can be tolerated. This has allowed the detection of the genetic systems controlling meiotic pairing, located on chromosomes 5B (Okamoto, 1957; Sears and Okamoto, 1958; Riley and Chapman, 1958) and 3D (Mello-Sampayo, 1971).

The genetic control of meiosis in diploid species has been studied by the use of meiotic mutants (Baker et al., 1976), but an analysis similar to that in hexaploid wheat has not been possible since nullisomics or monosomics are lethal. However, monosomy or nullisomy can be tolerated by diploid species when compensating homoeologous chromosomes are present. Such compensated aneuploids would allow a study of factors involved in genetic control of meiosis in diploids.

To test the effect of the missing chromosomes in hypoaneuploids on meiotic pairing, comparison is made between the pairing observed in euploid rye-triticale hybrids $(A B R R, 2 n=28)$ and that of three hypoaneuploid $A B R R$ hybrids. Such hybrids, of course, may not be considered diploids sensu strictu, but almost all pairing involves two sets of rye chromosomes. 


\section{Material ANd Methods}

Two aneuploid $A B R R$ hybrids with $2 n=26$ chromosomes and five $A B R R$ euploid hybrids with $2 n=28$ chromosomes, obtained from the cross hexaploid triticale $(A A B B R R ; 2 n=6 x=42)$ by Secale cereale $(R R$, $2 n=14$ ) and kindly supplied by Dr Lacadena, were analyzed. Three lines $(1,2$, and 3$)$ of $A B R R$ euploid hybrids $(2 n=28)$ and one aneuploid with $2 n=27$ (detected in line 2 ) were obtained from the following crosses:

Line 1, five plants; "Cachirulo" triticale $(A A B B R R, 2 n=6 x=42) \times S$. cereale cv. "Ailés" $(2 n=14)$.

Line 2, six plants; "Cachirulo" triticale $\times S$. cereale cv. "JNK" without $B$-chromosomes $(2 n=14)$.

Line 3, six plants; "Cachirulo" triticale $\times S$. cereale cv. "JNK" with $B$ chromosomes $(2 n=14+2 B$, and $2 n=14+4 B)$. All plants in this line carried two $B$-chromosomes $(2 n=28+2 B)$.

These lines were $C$-banded using the procedure of Giráldez et al. (1979).

\section{RESUlts}

\section{(i) Meiotic pairing}

The pairing data obtained in both euploid and aneuploid hybrids are presented in table 1 . In the euploid hybrids some rye chromosomes failed to pair, and some wheat chromosomes were involved in homoeologous pairing; the latter can be inferred from the occurrence of PMCs with less

TABLE 1

Mean values of meiotic pairing in euploid and aneuploid ABRR hybrids both obtained from the cross hexaploid triticale (AABBRR) by Secale cereale (RR) and studied using the Feulgen technique

\begin{tabular}{|c|c|c|c|}
\hline \multirow[b]{2}{*}{ Pairing } & \multirow{2}{*}{$\begin{array}{c}\text { Euploid } A B R R \\
\text { hybrids }(2 n=28)^{*}\end{array}$} & \multicolumn{2}{|c|}{$\begin{array}{l}\text { Aneuploid } A B R R \text { hybrids } \\
\qquad(2 n=26)\end{array}$} \\
\hline & & 1042 & 1606 \\
\hline Bivalents & $6 \cdot 65 \pm 0 \cdot 14$ & $5 \cdot 08 \pm 0 \cdot 25$ & $2.93 \pm 0.30$ \\
\hline Trivalents & $0.17 \pm 0.04$ & $0.06 \pm 0.05$ & $0.02 \pm 0.03$ \\
\hline Quadrivalents & $0.02 \pm 0.01$ & - & $0.01 \pm 0.02$ \\
\hline Bound arms & $9.03 \pm 0.20$ & $6.65 \pm 0.36$ & $3.23 \pm 0.35$ \\
\hline PMCs with less than seven associations, $\%$ & 37.83 & 85 & 100 \\
\hline PMCs with less than fourteen univalents, $\%$ & $37 \cdot 01$ & 15 & 2 \\
\hline Total PMCs & 489 & 100 & 100 \\
\hline
\end{tabular}

* The number of PMCs analyzed per plant was respectively 100 in three cases and 91 and 98 in the other two.

than fourteen univalents and from the occurrence of trivalents and quadrivalents. We assumed that multivalent associations did not include rye-rye translocations, since if this was the case there would be a higher frequency of quadrivalents than trivalents, but this was not so.

Aneuploid hybrids show lower pairing levels than euploid hybrids. Assuming that the two missing chromosomes have no effect on the pairing 


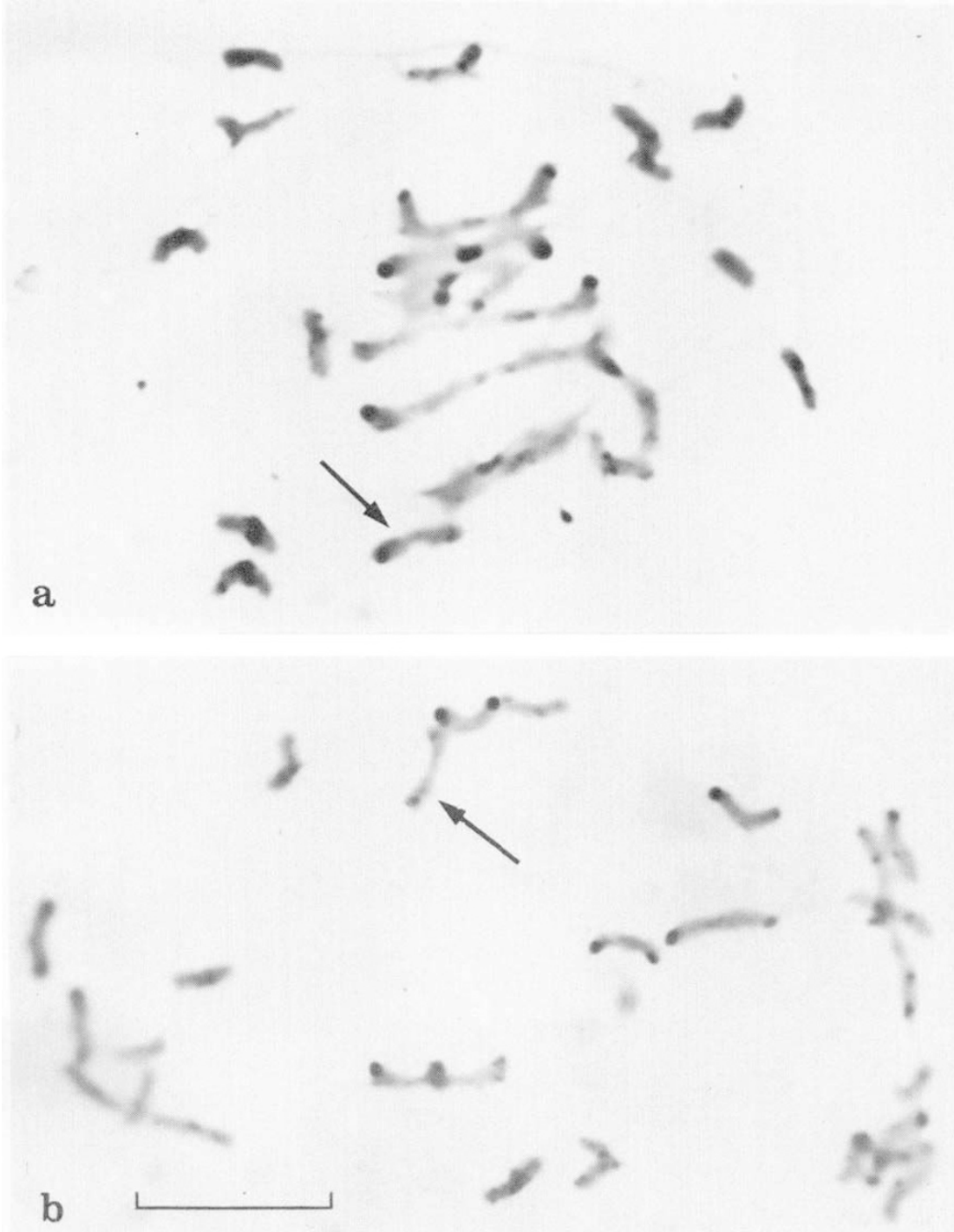

FIG. 1.-Metaphases I of a mono-5R $A B R R$ plant $(2 n=27)$ obtained from the cross "Cachirulo" triticale by Secale cereale cv. "JNK" without B-chromosomes and stained with $C$-banding. (a) 6 rye bivalents, 1 wheat bivalent (chromosomes are already at anaphase 1), 12 wheat univalents and chromosome 5R as univalent (arrow) showing its secondary constriction and its subterminal $C$-band (this chromosome also shows a telomeric band on the short arm). (b) 1 rye bivalent and 25 univalents, centromere position (arrow) on the submetacentric chromosome $5 R$ is indicated. Bar represents $10 \mu \mathrm{m}$. 
of the remaining chromosomes, the following three alternatives could be expected: (1) If the two chromosomes lost were both from wheat ( $A$ or $B$ ) the expected pairing values would be very close to that of euploid hybrids; (2) if the missing chromosomes were one from rye and the other from wheat $(A$ or $B$ ) the expected pairing values would be about six bivalents; (3) if two non-homologous rye chromosomes were lost there would be around five bivalents. The latter could be the case in aneuploid 1042 with a mean of 5.08 bivalents per cell. The possibility that two rye homologous chromosomes were lost is not considered, since, it assumes the formation of hypoaneuploid pollen grains. Aneuploid 1606 (2.93 bivalents per cell) differs greatly from any of the above predictions. This relatively low pairing suggests that one or both missing chromosomes in this aneuploid are required for a regular meiotic pairing of homologous rye chromosomes.

\section{(ii) C-banding}

The aneuploid with $2 n=27$ chromosomes detected in line 2 was shown to be monosomic for a submetacentric rye chromosome, which appeared unpaired at metaphase I. Therefore, any of the three submetacentric chromosomes $4 \mathrm{R} / 7 \mathrm{R}, 5 \mathrm{R}$ or $6 \mathrm{R}$ of the rye complement could be involved in the monosomy. Two cytological markers, namely, a secondary constriction frequently observed (Bielig and Driscoll, 1970) and a thin subterminal heterochromatic band (Darvey and Gustafson, 1975; Giráldez et al., 1979) both in the long arm (fig. 1) indicated that the unpaired submetacentric chromosome corresponded to $5 \mathrm{R}$.

The pairing levels are clearly lower in the mono-5R plant than in euploid hybrids (table 2), especially those referring to bound arms per cell. The

TABLE 2

Mean values of meiotic pairing in three euploid ABRR lines $(2 \mathrm{n}=28)$ and one mono-5R ABRR plant $(2 \mathrm{n}=27)$ obtained from the cross hexaploid triticale (AABBRR) by Secale cereale (RR) and analyzed using $C$-banding. Line 3 carries $2 B$-chromosomes of rye

Pairing

Rye bivalents

Rye bound arms

Wheat bivalents

Wheat bound arms

Wheat-rye associations

(biv. + triv.)

Total PMCs
Euploid $A B R R$ lines*

1

$6.44 \pm 0.06$

$10 \cdot 84 \pm 0.15$

$2 \cdot 06 \pm 0 \cdot 11$

$2 \cdot 42 \pm 0 \cdot 14$

$0 \cdot 11 \pm 0 \cdot 03$

500
2

$6 \cdot 49 \pm 0 \cdot 06$

$10 \cdot 28 \pm 0 \cdot 15$

$2.41 \pm 0.09$

$2 \cdot 90 \pm 0 \cdot 12$

$0 \cdot 01 \pm 0 \cdot 01$

740

\section{3}

$6 \cdot 63 \pm 0 \cdot 04$

$11 \cdot 18 \pm 0 \cdot 12$

$2.25 \pm 0.09$

$2 \cdot 62 \pm 0.11$

$0.02 \pm 0.01$

750
Aneuploid mono-5R

$4 \cdot 07 \pm 0 \cdot 16$

$5 \cdot 20 \pm 0 \cdot 24$

$0 \cdot 82 \pm 0 \cdot 10$

$0.90 \pm 0.11$

$0 \cdot 01 \pm 0 \cdot 01$

235

* In line 1100 PMCs per plant were analyzed, in line 2100 PMCs per plant in four and 90 and 250 in the other two plants, and in line 3100 PMCs per plant in five plant and 250 in the other one.

mean values of bound arms decreased to 50 per cent for rye homologous pairing and to 65 per cent for homoeologous wheat pairing. Such data clearly indicate that the $5 \mathrm{R}$ chromosome is both a strong promoter of preferential homologous pairing, and also affects homoeologous pairing in these rye-triticale hybrids. 


\section{Discussion}

From the results it is evident that hypoaneuploidy may be tolerated when homoeologous chromosomes are also present to compensate for the deficiency. The localization of genetic factors controlling meiotic pairing in hybrids may be achieved using such chromosome combinations.

The three aneuploids probably originated in triticale, the female parent; the reasons for drawing this conclusion are (1) pairing failure, which mainly affects rye chromosomes, is frequent in triticales (Scoles and Kaltsikes, 1974); (2) compensation of the missing chromosomes by homoeologous chromosomes may be possible; (3) it is improbable that hypo-hapoid gametes were formed in the pollen.

The differences observed between the mono-5R plant and euploid $A B R R$ hybrids in meiotic pairing indicate that chromosome $5 \mathrm{R}$ is a strong promoter of rye homologous pairing. One dose of $5 R$ apparently is not enough to meet all requirements, and its deficiency is not compensated by any of the wheat chromosomes present.

The results observed in aneuploid 1606 suggest that one (or two) chromosome(s) controlling preferential homologous rye pairing were lost. Although there are wheat chromosomes which carry factors promoting meiotic pairing (Sears, 1976), these were probably not lost; if rye promoter chromosomes were also present the expected pairing would be more than that observed. This is supported by the high level of rye pairing observed in plants $(0-7) A(0-7) B R R$ carrying 6,7 , and 8 wheat chromosomes (Naranjo and Lacadena, 1980). Therefore, the chromosome(s) lost in aneuploid 1606 is probably a rye chromosome. We do not know whether there is any other rye chromosome besides $5 \mathrm{R}$ affecting rye meiotic pairing. However, on the basis of the most likely constitution of the 1042 aneuploid, as suggested by its meiotic pairing, it seems that some other rye chromosomes have no effect on pairing.

Chromosome 5R also promotes homoeologous pairing between wheat chromosomes as can be deduced from the decrease observed in the mono5R plant. This activity may be included among the promotive effects of rye chromosomes on wheat homoeologous pairing (Miller and Riley, 1972; Riley, Chapman and Miller, 1973; Lelley, 1976; Dvorak, 1977; Bernard and Bernard, 1978; Jouve and Montalvo, 1978; Naranjo, Lacadena and Giráldez, 1979). Riley, Chapman and Miller (1973) suggest that the rye promotive effect is mediated by chromosome $5 \mathrm{R}$ and more specifically by its short arm, the suppressor activity detected in the long arm being lower in effectiveness. On the other hand, Lelley (1976) suggests that in the rye species Secale cereale and $S$. montanum the promoter system of homeologous pairing consists of more than two alleles and may be located on different chromosomes.

The euploid hybrids show lower total pairing levels $(6.65$ bivalents per cell) than the $C$-banded euploid hybrids (8.50, 8.90, and 8.88). Likewise, differences exist between the above values and those obtained by different authors. Lelley (1975) reported 5.77, 6.39, and 6.83 bivalents per cell respectively for three different $A B R R$ genotypes; Bernard and Bernard, (1978) 7.9 bivalents per cell; Jouve and Montalvo, (1978) 6.7, 8.8 and 9.5 bivalents per cell respectively for three plants derived from the same cross. Soler et al. (1980) reported data showing differences affecting both 
homologous and homoeologous pairing. Homologous pairing variation may be correlated with the presence or absence of rye telomeric heterochromatin (Merker, 1976; Naranjo and Lacadena, 1980).

It is also worth mentioning that the indiscriminate promotive activity of pairing (homologous and homoeologous) of chromosome 5R differs from that of the $P h$ locus of hexaploid wheats, which acts as a suppressor of homoeologous pairing (Okamoto, 1957; Sears and Okamoto, 1958; Riley and Chapman, 1958) and, therefore the genetic system located on chromosome $5 \mathrm{R}$ is essentially different from $P h$. Three likely sources of $P h$ have been suggested (Dover and Riley, 1972): (1) it was already present in the diploid species from which the $\mathbf{B}$ genome was derived, (2) it appeared by transfer from an accessory chromosome to chromosome $5 \mathrm{~B},(3)$ it originated by mutation some time after the formation of the $A A B B$ polyploid. In relation to the first possibility, suppressors have been detected in diploids but none with a power similar to $P h$ (Sears, 1976). On the other hand, contradictory results concerning a possible suppressor activity of chromosome 5R have been reported by Bielig and Driscoll (1970) and Riley, Chapman and Miller (1973). Origin by mutation includes two possibilities: duplication or greater multiplication of the locus which contains a suppressor gene (Sears, 1976) and mutation of a promoter gene to $\mathrm{Ph}$ (Felman, 1968). Our results indicate that a promoter activity with similar intensity but different character to that of $P h$ is present in diploid rye and it is located on the same homoeologous group as $P h$. On the assumption that other diploid species in the Triticinae are probable carriers of genetic systems like that of chromosome $5 \mathrm{R}$, which control their meiotic pairing, the idea that mutation of a promoter gene may be the origin of $P h$ is realistic.

Acknowledgments. - We thank Dr Lacadena for supplying a sample of $A B R R$ hybrids and Dr Rubio for his helpful comments.

\section{REFERENCES}

BAKER, B. S., CARPENTER, A. T., ESPOSITO, M. S., ESPOSITO, R. S., AND SANDLER, L. 1976. The genetic control of meiosis. Ann. Rev. Genet., 10, 53-134.

BERNARD, M., AND BERNARD, S. 1978. Methods of gene transfer from bread wheat and rye to hexaploid triticale. Proc. 8th Congr. Eucarpia, Madrid, Spain, 181-189.

BIELIG, M. L., AND DRISCOLL, C. J. 1970. Substitution of rye chromosome 5RL for chromosome 5B of wheat and its effects on chromosome pairing. Genetics, 65, 241-247.

DARVEY, N. L.. AND GUSTAFSON, J. P. 1975. Identification of rye chromosomes in wheat-rye addition lines and triticale by heterochromatin bands. Crop Sci., 15, 239-243.

DOVER, G. A., AND RILEY, R. 1972. Prevention of pairing of homoeologous meiotic chromosomes of wheat by an activity of supernumerary chromosomes of Aegilops. Nature, 240, $159-161$.

DVORAK, J. 1977. Effect of rye on homoeologous chromosome pairing in wheat $\times$ rye hybrids. Can. J. Genet. Cytol., 19, 549-556.

FELDMAN, M. 1968. Regulation of somatic association and meiotic pairing in common wheat. Proc. 3rd Int. Wheat Genet. Symp., Camberra, Aust. Acad. Sci., 31-40.

FELDMAN. M. 1978. New evidence on the origin of the B genome of wheat. Proc. Sth Int. Wheat Genet. Symp., New Delhi, 120-132.

GirÁldez, R.. CERMEÑo, M. C., AND ORELlANA, J. 1979. Comparison of C-banding pattern in the chromosomes of inbred lines and open pollinated varieties of rye. $Z$. Pflanzenzüchtg., 38, 40-48.

JOUVE. N., AND MONTALVO. D. 1978. Meiotic behaviour in hybrids between $6 x$ triticale and Secale cereale. Proc. 8th Eucarpia Congr., Madrid, Spain, 191-197. 
KIHARA, H. 1919. Uber cytologische studien bei einigen Getreidearten. I. Spezies-Bastarde des weizens und weizenroggen-Bastad. Bot. Mag. Tokyo, 33, 17-38.

LELLEY, T. 1975. Genic control of pairing of rye chromosomes in triticale. Z. Pflanzenzüchtg., $75,24-29$.

LELLEY, T. 1976. Induction of homoeologous pairing in wheat by genes of rye suppressing chromosome 5B effect. Can. J. Genet. Cytol., 18, 485-489.

McFADDEN, E. S., AND SEARS, E. R. 1946. The origin of Triticum spelta and its free threshing relatives. $J$. Heredity, 37, 81-89, 107-116.

MELLO-SAMPAYO, T. 1971. Genetic regulation of meiotic chromosome pairing by chromosome 3D of Triticum aestivum. Nature New Biol., 230, 22-23.

MERKER, A. 1976. The cytogenetic effect of heterochromatin in hexaploid triticale. Hereditas, $83,215-222$.

MILLER, T. E., AND RILEY, R. 1972. Meiotic chromosome pairing in wheat-rye combinations. Genét. Ibér., 24, 241-250.

NARANJO, T., LACADENA, J. R., AND GIRÁlDEZ, R. 1979. Interaction between wheat and rye genomes on homologous and homoeologous pairing. Z. Pflanzenzüchtg., 82, 289-305.

NARANJO, T., AND LACADENA, J. R. 1980. Interaction between wheat chromosomes and rye telomeric heterochromatin on meiotic pairing of chromosome pair $1 \mathbf{R}$ of rye in wheat-rye derivatives. Chromosoma (Berl.), 81, 249-261.

OKAмото, M. 1957. Asynaptic effect of chromosome V. Wheat Inf. Serv., 5, 6.

RILEY, R., AND CHAPMAN, V. 1958. Genetic control of the cytologically diploid behaviour of hexaploid wheat. Nature, 182, 713-715.

RILEY, R., CHAPMAN, V., AND MILLER, T, E. 1973. The determination of meiotic chromosome pairing. Proc. 4th Int. Wheat Genet. Symp., Missouri, Columbia, 731-738.

RILEY, R., UNRAU, J., AND CHAPMAN, V. 1958. Evidence on the origin of the B genome of wheat. J. Heredity, 49, 90-98.

SAX, K. 1922. Sterility in wheat hybrids. II. Chromosome behaviour in partially sterile hybrids. Genetics, 7, 513-522.

SCOLES, G. J., AND KALTSIKES, P. J. 1974. The cytology and cytogenetics of triticale. Z. Pflanzenzüchtg., 73, 13-43.

SEARS, E. R. 1952. Homoeologous chromosomes in Triticum aestivum. Genetics, 37, 624.

SEARS, E. R. 1976. Genetic control of chromosome pairing in wheat. Ann. Rev. Genet., 10, 31-51.

SEARS, E. R., AND OKAMOTO, M. 1958. Intergenomic chromosome relationships in hexaploid wheat. Proc. X Int. Congr. Genet., 2, 258-259.

SOlER, C., MONTALVO. D. E., AND JOUVE, N. 1980. Secondary associations of univalents chromosomes in hybrids of hexaploid triticale and rye and wheat. J. Heredity, 71, 408-410. 